\title{
Health professionals' barriers in the management, evaluation, and treatment of neonatal pain
}

\author{
Barreiras dos profissionais de saúde no manuseio, avaliação e tratamento da dor neonatal
}

Marialda Moreira Christoffel ${ }^{1}$, Danielle Lemos Queridoํ, Ana Luiza Dorneles da Silveira², Bruna Nunes Magesti ${ }^{1}$, Ana Letícia Monteiro Gomes $^{1}$, Ana Claudia Coelho Santos da Silva ${ }^{1}$

DOI 10.5935/2595-0118.20190007

\section{ABSTRACT}

BACKGROUND AND OBJECTIVES: Despite the solid results on pain management strategies in neonatology, it is necessary to identify and explore the barriers that may hamper the attention to pain and the implementation of the scientific evidence widely disseminated in the literature in the care practice. The objective of this study was to describe the barriers encountered by the healthcare professionals of a neonatal intensive care unit regarding the management, evaluation, and treatment of newborn pain.

METHODS: Descriptive, exploratory, quantitative study carried out in a maternity hospital in the city of Rio de Janeiro. Forty-two nursing technicians, 22 nurses, 20 physicians, and 2 physiotherapists participated in the study. The data was collected in an interview using a form and the data was analyzed by descriptive statistics.

RESULTS: Among the barriers found it stands out the lack of training on neonatal pain, no use of scales, the absence of routine and protocols for the treatment of pain, and the need for greater safety for the evaluation and treatment of pain. It was also observed that there is a gap between knowledge and care practice in the unit.

CONCLUSION: The identification of these barriers is essential to establish strategies based on knowledge-transfer to overcome the obstacles and improve the care given to newborns in the neonatal intensive care unit.

Keywords: Neonatal intensive care units, Newborn, Pain.

Marialda Moreira Christoffel - (Dhttps://orcid.org/0000-0002-4037-8759;

Danielle Lemos Querido - Dhttps://orcid.org/0000-0003-4895-296X;

Ana Luiza Dorneles da Silveira - (Dhttps://orcid.org/0000-0003-4126-7919;

Bruna Nunes Magesti - (Dhttps://orcid.org/0000-0001-9901-6659;

Ana Leticia Monteiro Gomes - (Dhttps://orcid.org/0000-0001-6220-5261;

Ana Claudia Coelho Santos da Silva - (Dhttps://orcid.org/0000-0001-5693-7378.

1. Universidade Federal do Rio de Janeiro, Escola de Enfermagem Anna Nery, Rio de Janeiro, RJ, Brasil.

2. Universidade Federal Fluminense, Escola de Enfermagem Aurora de Afonso Costa, Niterói, RJ, Brasil.

Submitted in June 13, 2018.

Accepted for publication in December 10, 2018.

Conflict of interests: none - Sponsoring sources: Conselho Nacional de Desenvolvimento Científico e TecnológicolCNPq. Bolsa de Pós-Doutorado Sênior (Processo número 158257/2011-1).

Correspondence to:

Rua Afonso Cavalcanti, 275 - Cidade Nova

20211-110 Rio de Janeiro, RJ, Brasil.

E-mail: brunanunesmagesti@yahoo.com.br

(C) Sociedade Brasileira para o Estudo da Dor

\section{RESUMO}

JUSTIFICATIVA E OBJETIVOS: Apesar de resultados solidificados sobre as estratégias de gestão da dor em neonatologia, faz-se necessário identificar e explorar as barreiras que dificultam a atenção à dor e a implementação na prática assistencial das evidências científicas amplamente difundidas na literatura. $\mathrm{O}$ objetivo deste estudo foi descrever as barreiras encontradas pelos profissionais de saúde de uma unidade de terapia intensiva neonatal em relação ao manuseio, avaliação e tratamento da dor de recém-nascidos.

MÉTODOS: Estudo descritivo exploratório, quantitativo, realizado em uma maternidade do município do Rio de Janeiro. Participaram 42 técnicos de enfermagem, 22 enfermeiros, 20 médi$\cos$ e 2 fisioterapeutas. Foi realizada uma entrevista utilizando-se um formulário para coleta de dados e estes foram analisados com uso de estatística descritiva.

RESULTADOS: Entre as barreiras encontradas destacam-se a ausência de treinamento sobre dor neonatal, a não utilização de escalas, ausência de rotina e protocolos para o tratamento da dor e a necessidade de maior segurança para a avaliação e o tratamento da dor. Observou-se, também, que existe uma lacuna entre o conhecimento e a prática assistencial na unidade.

CONCLUSÃO: A identificação dessas barreiras torna-se essencial para que se busquem estratégias fundamentadas na transferência de conhecimento para vencer os obstáculos e melhorar a assistência prestada aos recém-nascidos na unidade de terapia intensiva neonatal.

Descritores: Dor, Recém-nascido, Unidades de terapia intensiva neonatal.

\section{INTRODUCTION}

Currently, health professionals responsible for the treatment and diagnosis of newborns (NB) admitted in the neonatal intensive care unit (NICU) recognize pain as a result of the procedures performed. However, there are barriers related to the knowledge of the pain management process, including the identification of the signs, evaluation, and treatment, that prevent its practice ${ }^{1,2}$.

International $^{3,4}$ and national ${ }^{1}$ studies about the knowledge, attitudes and practices of health and nursing professionals on the management of neonatal pain show important gaps in the understanding of fundamental neurobiological mechanisms that rule the development of the somatosensory system and its 
response to potentially painful stimuli, pain assessment, and non-pharmacological and pharmacological interventions to relieve the pain during ongoing NB care.

NB's in NICU's that require longer hospitalization undergo several daily painful procedures 5 . There is strong evidence for the use of non-pharmacological interventions (skin-to-skin contact, breastfeeding, and non-nutritive sucking) as well as analgesic methods that are available but are not yet incorporated into the NICU care practice ${ }^{1.2}$.

Untreated pain can have negative effects on the newborn, especially on premature infants who are exposed to pain and stress during a phase that is undergoing rapid brain development with the nerve pathways in the process of development. In addition, it has long-term consequences such as slower postnatal growth and neurological development, high cortical activation and changes in brain development, the temperament of negative affectivity, cognitive and motor deficit ${ }^{6}$.

The health professional must act as an advocate of the NB's rights not to feel pain when there are means to avoid it ${ }^{7}$. Therefore, it is critical that the evidence available on the use of effective measures to manage pain be used to improve the quality of care provided to the $\mathrm{NB}^{2}$.

Pain prevention should be the goal of the team that assists the $\mathrm{NB}$, not only because it is legal and ethical care, but also to avoid the exposure of these babies to repeated procedures that negatively impact their neurodevelopment ${ }^{8}$.

Despite the solid results on pain management strategies in neonatology, it is necessary to identify and explore the barriers that undermine the attention to pain and the implementation of the scientific evidence widely disseminated in the literature in the care practice ${ }^{9,10}$.

The objective of this study was to describe the barriers encountered by health professionals of a NICU regarding management, assessment, and treatment of pain in newborns.

\section{METHODS}

This is a descriptive, cross-sectional study with a quantitative approach, carried out at the NICU of a teaching maternity ward in the city of Rio de Janeiro, which provides multi-professional assistance offering specific care to pregnant women and high-risk newborns.

The health professionals of the unit who provide direct assistance to the NB were included, and the others were excluded. The study population comprised 96 health professionals working in the institution. After the invitation to participate, the non-probabilistic sample was of 86 interviewees, among them 42 nursing assistants/technicians, 22 nurses, 20 physicians, and two physiotherapists.

Data collection was from February to April 2013. Each participant received a copy of the semistructured questionnaire with open and closed questions after signing the Free and Informed Consent Term (FICT). Each questionnaire was in a sequentially numbered brown envelope, ensuring the participant's anonymity.
The participants had three days to return the questionnaire, with the envelope sealed and put in a box identified with the name of one of the researchers, who remained in the sector during the collection period.

The variables extracted from the questionnaire referred to the profile of the health professionals, including gender, age, educational background, professional qualification, functional link with the unit, work regime and number of employment relationships, job satisfaction, qualification/orientation in neonatal pain and knowledge, practices and attitude in pain management. The last question was the description of five barriers related to the pain management process of the NB in the NICU, in order of priority.

The study was approved by the Research Ethics Committee of the Maternity School of the Federal University of Rio de Janeiro, opinion number 186.719 of $01 / 18 / 2013$, following all the ethical principles determined in Resolution 466/12 of the National Health Council.

\section{Statistical analysis}

The data were organized in Microsoft Excel spreadsheet software, version 2010 and double typing with the correction of divergences and inconsistencies was used as the reliability criterion. The analysis was done by descriptive statistics.

\section{RESULTS}

Of the 86 professionals interviewed, the majority were female $(89.5 \%)$. Of the male professionals, six $(7.0 \%)$ were nursing technicians and three $(3.5 \%)$ doctors. The average age of the participants was 34.1 years, with a standard deviation of 7.4.

Regarding the educational background, among nursing technicians, three $(3.5 \%)$ had an academic degree, one $(1.2 \%)$ had neonatal nursing specialization, and four (4.7\%) were attending the undergraduate course. The majority $(81.8 \%)$ of nurses, all the physicians, and all the physiotherapists had a lato sensu postgraduate degree or were attending stricto sensu postgraduate course.

Regarding the functional link in the study unit, 25 (29.1\%) were civil servants, and 54 (62.8\%) had a cooperative link/were hired. Regarding the work regime, the majority $(92.8 \%)$ of the nursing technicians and $63.7 \%$ of the nurses worked on a 24 -hour duty by 120 -hour rest format, being possible to run extra shifts. Regarding the other professionals, it was observed that $35 \%$ of the physicians had a 20h-weekly work journey and $100 \%$ of the physiotherapists a 24 h-weekly work journey.

Most of the professionals $(76.7 \%)$ had more than one job. Nine (21.4\%) technicians, 8 (36.4\%) nurses, 10 (50\%) physicians, and one $(50 \%)$ physiotherapist did not work in the neonatal unit in their other job. When evaluating the working conditions in the unit surveyed, 33 (78.6\%) nursing technicians, 18 (31.8\%) nurses, seven $(35 \%)$ physicians, and one $(50 \%)$ physiotherapist said they were satisfied with those conditions.

Although the majority of the health professionals (66.3\%) having said that they obtained information about neonatal pain during their vocational, undergraduate or lato sensu graduate training, the most cited source of information was the man- 
agement directions and/or guidance from other healthcare professionals.

Concerning the knowledge of care routine related to pain management, $10(23.8 \%)$ technicians, seven $(31.8 \%)$ nurses and one (5\%) physician reported that there is a pain protocol that included neonatal pain scales.

Regarding the barriers pointed out by the health professionals related to the process of pain management, such as assessment and treatment, we identified the individual and teamwork connection with the complexity of the care of the newborn and with the institutional system.

The barriers related to the individual and teamwork that most stood out were the need for training on the subject of pain, followed by lack of communication among health professionals (Table 1).
The barriers related to the complexity of NB care highlighted the hostile, noisy and overly bright environment of the NICU, the need for different care procedures and consequent excessive manipulation, the clinical state of the NB, the use of drugs such as sedatives and opioids and the valorization of heavy over light technology (Table 2).

Finally, the barriers related to the institutional system that outstood were the lack of routine and protocol to assess and treat neonatal pain, followed by overcrowding (Table 3 ).

\section{DISCUSSION}

The barriers pointed out by health professionals in the pain management process that mostly stood out touched individual

Table 1. Distribution of barriers identified by health professionals from the perspectives of the individual and teamwork

\begin{tabular}{|c|c|c|c|c|}
\hline Barriers identified & $\begin{array}{l}\text { TEC } \\
\text { n (\%) }\end{array}$ & $\begin{array}{c}\text { NR } \\
\text { n (\%) }\end{array}$ & $\begin{array}{c}\text { MD } \\
\text { n (\%) }\end{array}$ & $\begin{array}{c}\text { PT } \\
\text { n (\%) }\end{array}$ \\
\hline Need for training on the subject of pain & $39(24.0)$ & $11(15.0)$ & $07(10.0)$ & $02(25.0)$ \\
\hline Lack of professional knowledge about pain assessment and treatment & - & $07(10.0)$ & $04(6.0)$ & $01(12.5)$ \\
\hline Professional's uncertainty regarding pain assessment and treatment & $08(4.9)$ & $03(4.0)$ & $03(4.0)$ & -- \\
\hline I don't see barriers & $01(0.6)$ & - & - & - \\
\hline Lack of communication among health professionals & $21(13.0)$ & $08(11.0)$ & $05(7.0)$ & $01(12.5)$ \\
\hline Relationship among professionals & $05(3.0)$ & - & - & - \\
\hline Beliefs and attitudes of health professionals & $04(2.0)$ & $04(6.0)$ & $03(4.0)$ & - \\
\hline
\end{tabular}

TEC = nursing technician; $\mathrm{NR}$ = nurse; $\mathrm{MD}$ = physician; $\mathrm{PT}$ = physiotherapist.

Table 2. Distribution of barriers identified by health professionals based on the complexity of the newborn care

\begin{tabular}{|c|c|c|c|c|}
\hline Barriers identified & $\begin{array}{l}\text { TEC } \\
\mathrm{n}(\%)\end{array}$ & $\begin{array}{c}\text { NR } \\
\mathrm{n}(\%)\end{array}$ & $\begin{array}{c}\text { MD } \\
\mathrm{n}(\%)\end{array}$ & $\begin{array}{c}\text { PT } \\
\text { n (\%) }\end{array}$ \\
\hline Neonatal intensive care unit environment (noise, brightness) & $07(4.3)$ & $01(1.0)$ & $04(6.0)$ & - \\
\hline Procedures (intubation, CPAP, bath, drug administration) & $12(7.3)$ & $02(3.0)$ & $01(1.0)$ & - \\
\hline Minimal handling/excessive handling & $08(4.9)$ & $04(4.0)$ & $03(3.0)$ & - \\
\hline Clinical status of the newborn (extreme premature, neuropathies) & $08(4.9)$ & $02(3.0)$ & $03(4.0)$ & $02(25.0)$ \\
\hline Newborn in humidified incubator & $01(0.6)$ & - & $01(1.0)$ & - \\
\hline Newborn using drugs (sedatives, opioids) & $02(1.3)$ & $04(6.0)$ & $03(4.0)$ & - \\
\hline Valorization of heavy technology over light technology & - & $02(3.0)$ & - & - \\
\hline
\end{tabular}

CPAP = continuous positive airway pressure; TEC = nursing technician; NR = nurse; MD = physician; PT = physiotherapist.

Table 3. Distribution of barriers identified by health professionals regarding the institutional system

\begin{tabular}{|c|c|c|c|c|}
\hline Barriers identified & $\begin{array}{l}\text { TEC } \\
\mathrm{n}(\%)\end{array}$ & $\begin{array}{c}\text { NR } \\
\mathrm{n}(\%)\end{array}$ & $\begin{array}{c}\text { MD } \\
\text { n (\%) }\end{array}$ & $\begin{array}{c}\text { PT } \\
\text { n (\%) }\end{array}$ \\
\hline Lack of routine and protocol to assess and treat neonatal pain & $20(12.0)$ & $07(10.0)$ & $13(19.0)$ & $02(25.0)$ \\
\hline Human Resources & $08(4.9)$ & $01(1.0)$ & $05(7.0)$ & - \\
\hline Working hours & - & $01(1.0)$ & - & - \\
\hline
\end{tabular}

TEC = nursing technician; $\mathrm{NR}$ = nurse; $\mathrm{MD}$ = physician; $\mathrm{PT}$ = physiotherapist. 
issues, teamwork, the complexity of the NB care and institutional issues.

The pain management process goes from the identification of the signs of pain manifested by the NB, the assessment using scales, action plan, and treatment. When referring to pain management, health professionals emphasized the need for training on the subject of pain due to the lack of knowledge regarding pain assessment and treatment, showing its impracticability.

Gaps in the knowledge of the team regarding the assessment, treatment, and management of neonatal pain have already been identified as obstacles in the effective management of pain ${ }^{10,11}$. Professional educational and training strategies translate to theoretical knowledge that is transferred to the practice of care, driving changes in this practice, and providing tools for these professionals. The presence of continuous education based on scientific evidence helps professionals to adopt effective and safe measures to control pain ${ }^{12}$.

Insufficient notes and remarks in the medical records also appeared as a barrier in this study. The professional should feel motivated and value his/her work by always registering it. However, it is worth mentioning that due to the lack of knowledge regarding the subject, the record is frail since the management of pain has not been translated as recognized care.

This record is part of the health information system, enables the ethical and legal support of the assistance, works as auditing and development instrument of the teaching and research in the nursing area ${ }^{13}$. The scientific deficiency in relation to pain makes the professional insecure and demotivated which can be leading factors to other problems.

The team that works in NICU can suffer from stress and lose motivation to work ${ }^{14}$, which is pointed out as a factor that makes difficult the assessment, treatment, and management of neonatal pain in the present study.

From terms of teamwork, the lack of communication among health professionals is pointed out as a barrier to the implementation of evidence in practice, as well as the group's beliefs and attitudes. This gap is present both among managers and care workers and among health workers on a shift generating lack of interprofessional collaboration and difficulty in sharing information ${ }^{15}$.

To humanize the care, it is necessary to establish adequate communication among the members of a team, resulting in greater proximity of the workgroup with consequent standardization of tasks. Failure in communication among different categories can lead to professional stress ${ }^{14}$.

Regarding the beliefs and attitudes that the group uses in relation to neonatal pain, it can be noted that some behaviors may be linked to the obsolete myths that due to the immaturity of the NB systems, especially premature NB, the perception of pain in this population would be negligible ${ }^{16}$.

The newborns in NICUs are exposed to innumerable invasive procedures and a stressful environment that brings a series of negative consequences to their neurodevelopment, making them susceptible to pain and stress ${ }^{14,17,18}$. In fact, the care of NBs admitted in the NICU involves complex care, surrounded by technologies that aim to reduce the morbidity and mortality of the NBs, seeking their survival with quality of life ${ }^{19}$.

In this sense, it is up to the professionals who work in the unit to develop mechanisms to overcome these barriers, elaborating strategies to minimize the impact of this environment on the NB recovery. Some suggestions such as the need to identify these difficulties and the implementation of a team or committee responsible for neonatal pain issues were pointed out ${ }^{9,20}$.

Regarding the barriers of the institutional and organizational system, the lack of routines and protocols to assess and treat neonatal pain were pointed out.

It is recognized that the healthcare based on protocols, especially those built with the participation of healthcare professionals, is likely to have a positive impact on the quality of pain assessment and its treatment. Structured guidelines and protocols provide a systematization for the treatment of neonatal pain and boost the outcomes, being useful instruments for the multifaceted management of pain, contributing to professional qualification and decision-making, as well as facilitating the incorporation of new technologies and the dissemination of knowledge $\mathrm{e}^{12,21}$.

Issues regarding the working hours of the professionals and the optimal number of human resources also appeared as difficulties. Since there are professionals with more than one job, it is possible that the working hours have also appeared as a difficulty for the management of pain, as this fact is reflected in an excessive workload.

In this sense, although there are tools to calculate the adequate number of professionals to the needs of the service, there is still shortness of professionals in health institutions, and it is recommended the elaboration of studies that correlate the sizing of personnel to the workload and the development of quality indicators associated with this issue ${ }^{22}$.

This observation by the participants can be an opportunity to review the amount of personnel that despite being in accordance with the current resolutions, need to carry out multifaceted care tasks. Thus, due to the complexity and the relevant nature of care in an entire and humanized way to the seriously or potentially seriously ill newborn, it becomes necessary a larger number of professionals to perform this work.

The absence of the parents was identified only by one of the professionals as a difficulty to assess, treat and manage pain. It was noticed that the lack of parents' involvement during the painful experience of hospitalized NB undermines the partnership between the professionals and the parents?

Therefore, it is recommended to involve the parents in the management of the infant's pain, contributing to a more humanized care. However, the work culture and the organizational characteristics of a NICU make this process very difficult ${ }^{9}$.

It is up to the health professional to brief the parents about the signs of pain, especially the mothers who most often experience the hospitalization of their children. Besides the briefing, these mothers should be invited to participate in care to be able to call the team at the first sign of discomfort or stress of their $\mathrm{NB}^{23}$. 
One limitation of the study was the non-participation of the unit service managers in the presentation of a good practice policy in pain management, bringing current evidence for changes in the clinical practice, consistently and systematically, in the continuous care of the newborn. Also, there is a need to discuss the competencies of each healthcare professional regarding the use of more complex pain scales and non-pharmacological and pharmacological measures in the relief of neonatal pain.

The identification of the barriers in this study led to the execution of a training course to build collective knowledge, the disclosure of the institutional material and incorporation of the practice in NB care. Thus, institutional actions were implemented crowned with the protocol for the non-pharmacological management of neonatal pain, currently available online and printed in a separate folder in the unit.

\section{CONCLUSION}

The present study showed that there are barriers and that neonatal services need to have educational programs to improve the clinical practice in the relief of neonatal pain.

\section{ACKNOWLEDGMENTS}

To the National Council for Scientific and Technological Development $C$ NPq. Brasília-DF, Brasil, for the support to conduct the study with the Postdoctoral Senior Fellowship (Process number 158257\2011-1).

\section{REFERENCES}

1. Soares AC, Caminha MF, Coutinho AC, Ventura CM. Pain in the neonatal unit: the knowledge, attitude and practice of the nursing team. Cogitare Enferm. 2016;21(2):1-10.

2. Sposito NP, Rossato LM, Bueno M, Kimura AF, Costa T, Guedes DM. Assessment and management of pain in newborns hospitalized in a Neonatal Intensive Care Unit: a cross-sectional study. Rev Lat Am Enfermagem. 2017;25:e2931. English, Portuguese, Spanish.

3. Anand KJ, Eriksson M, Boyle EM, Avila-Alvarez A, Andersen RD, Sarafidis K, et al. Assessment of continuous pain in newborns admitted to NICUs in 18 European countries. Acta Paediatr. 2017;106(8):1248-59.
4. Lago P, Frigo AC, Baraldi E, Pozzato R, Courtois E, Rambaud J, et al. Sedation and analgesia practices at Italian neonatal intensive care units: results from the EUROPAIN study. Ital J Pediatr. 2017;43(1):26.

5. Courtois E, Droutman S, Magny JF, Merchaoui Z, Durrmeyer X, Roussel C, et al Epidemiology and neonatal pain management of heelsticks in intensive care units: EPIPPAIN 2, a prospective observational study. Int J Nurs Stud. 2016;59:79-88.

6. Valeri BO, Holsti L, Linhares MB. Neonatal pain and developmental outcomes in children born preterm: a systematic review. Clin J Pain. 2015;31(4):355-62.

7. Conselho Nacional dos Direitos da Criança e do Adolescente. Direitos da Criança e do Adolescente Hospitalizados. Resoluçấo $n^{\circ} 41$ de outubro de 1995. Diário Oficial da Uniăo. Brasília, DF, 17 out. 1995.

8. Prevention and management of procedural pains in the neonate. APP American Academy of Pediatrics. Committee on Fetus and Newborn. Section on Anesthesiology and Pain Medicine. Pediatrics. 2016;137(2):e20154271.

9. Marfurt-Russenberger K, Axelin A, Kesselring A, Franck LS, Cignacco E. The experiences of professionals regarding involvement of parent $s$ in neonatal pain management. J Obstet Gynecol Neonatal Nurs. 2016;45(5):671-83.

10. Abdel Razeq NM. Barriers that impede the provision of pain care to neonates by nurses in Jordan. J Obstet Gynecol Neonatal Nurs. 2016;45(3):371-7.

11. Cong X, Delaney C, Vazquez V. Neonatal nurses' perceptions of pain assessment and management in NICUs: a national survey. Adv Neonatal Care. 2013;13(5):353-60.

12. Christoffel MM, Castral TC, Dare MF, Montanholi LL, Scochi CG. Knowledge of healthcare professionals on the evaluation and treatment of neonatal pain. Rev Bras Enferm. 2016;69(3):516-22.

13. Carneiro SM, Dutra HS, Costa FM, Mendes SE, Sena CA. Uso de abreviaturas nos registros de enfermagem em um hospital de ensino. Rev Rene. 2016;17(2):208-16.

14. Ministério da Saúde. Secretaria da Atençấo à Saúde. Departamento de Açốes Programáticas Estratégicas. Atençâo humanizada ao recém-nascido de baixo peso: Método canguru: manual técnico. Brasília: Ministério da Saúde; 2013.

15. Puchalski Ritchie LM, Khan S, Moore JE, Timming C, van Lettow M, Vogel JP, et al Low- and middle-income countries face many common barriers to implementation of maternal health evidence products. J Clin Epidemiol. 2016;76:229-37.

16. Prestes AC, Balda RC, Santos GM, Rugolo LM, Bentlin MR, Magalhăes M, et al Painful procedures and analgesia in the NICU: what has changed in the medical perception and practice in a ten-year period? J Pediatr. 2016;92(1):88-95.

17. Mörelius E, He HG, Shorey S. Salivary cortisol reactivity in preterm infants in neonatal intensive care: an integrative review. Int J Environ Res Public Health. 2016;13(3):pii:E337.

18. Martins SW, Dias FS, Enumo SR, Paula KM. Pain assessment and control by nurses of a neonatal intensive care unit. Rev Dor. 2013;14(1):21-6.

19. Ministério da Saúde. Secretaria de Atenção à Saúde. Departamento de Açōes Programáticas e Estratégicas. Atençăo à saúde do recém-nascido: guia para os profissionais de saúde, v.4. Brasília: Ministério da Saúde; 2014.

20. Purteimur S, Nouri M. The barriers to pain management in the neonatal intensive care unit. Pediatric Crit Care Med. 2014;15(Suppl 4):214.

21. Lim Y, Godambe S. Prevention and management of procedural pain in the neonate: an update, American Academy of Pediatrics 2016. Arch Dis Child Educ Pract Ed. 2017;102(5):254-6.

22. Menegueti MG, Nicolussi AC, Scarparo AF, Campos LF, Chaves LD, Laus AM. Nursing personnel staffing in hospital services: an integrative literature review. Rev Eletr Enferm. 2013;15(2): 551-63.

23. Santos MC, Gomes MF, Capellini VK, Carvalho VC. Maternal assessment of pain in premature infants. Rev Rene. 2015;16(6):842-7. 